https://doi.org/10.48009/1_iis_2006_253-258

\title{
THE MARKET FOR IS AND MIS SKILLS AND KNOWLEDGE: ANALYSIS OF ON-LINE JOB POSTINGS
}

\author{
G. Kent Webb, San Jose State University, webb_k@cob.sjsu.edu
}

\begin{abstract}
As part of an effort to keep an MIS curriculum in line with market demand, a sample of job postings from Monster.com was taken over a one year period. A list of most frequently requested skills and knowledge was created for jobs requiring a bachelor's degree in information systems (IS) or management information systems (MIS). The results support the importance of verbal and written communications. The skills lists were further broken down into four traditional career paths: database, networking, systems analysis, and programming. A cluster analysis of the data revealed three basic skill groups: analysis, programming, and networking.
\end{abstract}

Keywords: Curriculum Design, Job Ads, Workplace Skills

\section{INTRODUCTION}

Professional societies such as the ACM provide model curriculums [1] to address general issues of curriculum design. As many researchers have noted, however, the choice of specific skills and knowledge to populate these courses is often left to individual faculty or departments [2] who may find it difficult to keep skills sets properly aligned with market demand. For example, this study began in an effort to resolve a controversy over what specific programming language or other skill should be included in an introductory course. The end process, discussed in the conclusion, was a mapping of current high demand skills into the overall curriculum to see what fine tuning might make graduates from our program more marketable. Research approaches to identify marketable skills have included surveys of managers who hire information systems talent [3], sampling from job postings in newspaper classified ads [4] or online job postings [5, 6], and even surveys of students [7].

Surveys of managers have tended to reveal a focus on general knowledge and learning ability, while surveys of classified ads found much more focus on technical skills [8]. More recently available on-line job postings, not faced with the severe space restrictions of newspaper classified ads, allow much more thorough job descriptions and have been more consistent with the results of manager surveys where general skills, such as written communication, were perceived to be of high importance.

\section{RESEARCH METHODOLOGY}

The research objective here is to determine what are the most marketable skills and technical knowledge in the current job market. A sample of 250 jobs posted on Monster.com from February 2005 to February 2006 was gathered for positions requiring a bachelor's degree in IS or MIS. A keyword search was done on "management information systems." For most job postings, the data reflect what appears under the heading "required skills". Some job postings made a distinction between skills and technical knowledge. Both groups of listings were included in this sample for analysis.

In listing the rankings, a paired samples test for the difference in means from variables taken from one sample was conducted. The significance value, "Sig." in the table (the p-value), identifies the probability that the difference is 0 for the next lower ranked skill.

A two-stage hierarchical cluster analysis was also conducted to see how skills might be grouped in the market. Clusters were determined automatically using Schwarz's Bayesian Criterion (BIC) and the log-likelihood distance measure.

\section{RESULTS}

This section first presents the overall results from the sampled job postings. Next, the list of requested skills was broken down by four traditional career paths: database, networking, systems analysis, and programming. Finally, the results from the cluster analysis are summarized.

\section{Top 30 Skills and Knowledge}

Among all jobs surveyed requiring a bachelor's degree in IS or MIS, the following were the 30 most often mentioned job skills and technical knowledge. Skills are listed as they appear in the job listing so the tables include some overlap such as for Excel and Microsoft Office. The significance column (Sig.) reports the two-tailed significance in the difference 
between the ranked skill and the next lower ranked skill, the p-value of the difference. For example, the value of 0.711 for the Number 1 ranked skill, written and verbal communications, indicates that there is a statistical tie for first place with systems analysis. In the next cell down, the 0.002 indicates a significant difference between the number two ranked skill, Systems Analysis, and the number three ranked skill, SQL.

Table 1. Top 30 Skills and Knowledge

\begin{tabular}{|c|c|c|c|}
\hline Rank & Skill/Knowledge & Percent & Sig. \\
\hline 1 & $\begin{array}{l}\text { Written \& Verbal } \\
\text { Communications }\end{array}$ & 51.2 & .711 \\
\hline 2 & Systems Analysis & 49.6 & .002 \\
\hline 3 & SQL & 36.0 & .526 \\
\hline 4 & Team Work & 33.2 & .293 \\
\hline 5 & Windows Server & 29.2 & .239 \\
\hline 6 & Visual Basic & 24.8 & .244 \\
\hline 7 & Oracle Database & 20.4 & .711 \\
\hline 8 & MS SQL & 19.2 & .740 \\
\hline 9 & Linux/Unix/Sol. & 18.0 & .806 \\
\hline 10 & Java & 17.2 & .239 \\
\hline 11 & MS Office & 14.0 & .887 \\
\hline 12 & PC Technology & 13.6 & .893 \\
\hline 13 & MS Access & 13.2 & .900 \\
\hline 14 & LAN Knowledge & 12.8 & .898 \\
\hline 15 & MS Excel & 12.4 & .898 \\
\hline 16 & Windows XP & 12.0 & .894 \\
\hline 17 & HTML & 11.6 & 1.00 \\
\hline 18 & TCP/IP & 11.6 & 1.00 \\
\hline 19 & WAN & 11.6 & .778 \\
\hline 20 & MS ASP & 10.8 & 1.00 \\
\hline 21 & Web Design & 10.8 & .887 \\
\hline 22 & MS.Net & 10.4 & .866 \\
\hline 23 & $\mathrm{C}$ & 10.0 & .447 \\
\hline 24 & MS Exchange & 8.0 & .724 \\
\hline 25 & MS IIS & 7.2 & .696 \\
\hline 26 & XML & 6.4 & .858 \\
\hline 27 & SAS & 6.0 & .848 \\
\hline 28 & Crystal Reports & 5.6 & 1.00 \\
\hline 29 & ERP & 5.6 & 1.00 \\
\hline 30 & Novell & 5.6 & 1.00 \\
\hline
\end{tabular}

The high values on many of the significance tests indicate that there are many statistical ties in the rankings. In terms of some specific pairings that were important to curriculum design issues, the data indicate that demand for Windows Server skills (including Server 2003, 2000, and NT) significantly exceeds that for the combined group of Linux/Unix/Solaris with a p-value of 0.001. Demand for Visual Basic exceeded that of Java with a p-value of .032. Demand for Oracle was statistically tied with Microsoft SQL. The next most commonly listed skills, in declining order of percentage of listings in the job postings, were: Perl, WebSphere, SAP, SAN, Cobol, VPN, DB2, Lotus-Domino, PHP, and EDI.

Four major career paths are represented in our MIS curriculum. Based on the survey, they are ranked below in order of appearance in job listings. Using a 0.05 statistical difference (maximum p-value), the database job area exceeds that for systems analysis and programming, but not for networking. The significance of the difference between networking and programming is about .065 , not quite exceeding the 0.05 standard.

Table 2. Major Job Areas

\begin{tabular}{|c|l|c|c|}
\hline Rank & Job Area & Percent & Sig. \\
\hline 1 & Database & 58.8 & .123 \\
\hline 2 & Networking & 51.6 & .675 \\
\hline 3 & Systems Analysis & 49.6 & .191 \\
\hline 4 & Programming & 43.6 & \\
\hline
\end{tabular}

The Sig. reports the probability that the ranked skill is tied with the next ranked skill, rather than significantly different. The percentages add to more than 100 given the significant overlap in these skills. $\mathrm{n}=250$

Jobs were classified as database if they required knowledge of an application such as Oracle. Jobs in the networking group required familiarity with an application such as Windows Server. Programming jobs listed at least one programming language as a required skill. The systems analysis jobs were less clearly defined, but were included into this category if requirements analysis or systems development and design were requested in the job description. Some jobs included more than one category of skills, so there is some overlap in the sample for each group.

\section{Top Skills and Technical Knowledge for Database Jobs}

Among job postings requiring knowledge of database applications, the top 20 skills and technical knowledge are listed below. Compared to the overall market, general knowledge of SQL ranked much higher. Surprisingly, Microsoft Excel skill also ranked significantly higher. Given the strong presence of Oracle in this market, related skills (non Microsoft) such as Linux/Unix/Solaris and Java also ranked higher than in the overall market. 
Table 3. Top Database Related Skills and Knowledge

\begin{tabular}{|c|l|c|}
\hline Rank & Skill/Knowledge & Percent \\
\hline 1 & SQL and Verbal & 61.2 \\
\hline 2 & $\begin{array}{l}\text { Written and } \\
\text { Communication }\end{array}$ & 52.4 \\
\hline 3 & Oracle & 35.3 \\
\hline 4 & MS-SQL & 32.7 \\
\hline 5 & Team Work & 30.6 \\
\hline 6 & Windows Server & 25.9 \\
\hline 7 & Systems Analysis & 25.2 \\
\hline 8 & Linux/Unix/Sol. & 25.2 \\
\hline 9 & Access & 22.4 \\
\hline 10 & Visual Basic & 21.8 \\
\hline 11 & Java & 19.0 \\
\hline 12 & Excel & 18.4 \\
\hline 13 & MS-Office & 16.3 \\
\hline 14 & HTML & 15.0 \\
\hline 15 & MS-ASP & 14.3 \\
\hline 16 & PC Technology & 13.0 \\
\hline 17 & NET & 12.9 \\
\hline 18 & C & 11.6 \\
\hline 19 & MS-IIS & 10.2 \\
\hline 20 & SAS & 10.2 \\
\hline 21 & Web Design & 10.2 \\
\hline 22 & Windows XP & 10.2 \\
\hline $\mathrm{n}=142$ & & \\
\hline
\end{tabular}

After the top 22, the next skills and knowledge most commonly listed were Crystal Reports, XML, TCP/IP, Exchange, WAN, DB2, Perl, LAN Cobol, ERP, WebSphere, PHP, and SAP.

\section{Top Skills and Technical Knowledge for Networking Jobs}

For jobs related to networking, the skills and technical knowledge listed in Table 4 appeared most frequently in job postings. Knowledge of Microsoft Windows Server topped the list with more than half of the jobs. The Linux/Unix/Solaris knowledge accounted for about a third of the jobs, nearly tied with basic knowledge of SQL.

Basic networking knowledge such as of LAN, WAN, and TCP/IP ranked in the top 10. Following this list in the rankings was: Novell, $\mathrm{C}$ programming, MSAccess, XML, XAN, Crystal Reports, MS-Excel, VPN, Web Design, and Perl.
Table 4. Top Networking Related Skills and Knowledge

\begin{tabular}{|c|l|c|}
\hline Rank & Skill/Knowledge & Percent \\
\hline 1 & Windows Server & 54.5 \\
\hline 2 & $\begin{array}{l}\text { Written \& Verbal } \\
\text { Communications }\end{array}$ & 52.3 \\
\hline 3 & Team Work & 42.4 \\
\hline 4 & Linux/Unix/Sol. & 34.1 \\
\hline 5 & SQL & 32.6 \\
\hline 6 & LAN & 24.2 \\
\hline 7 & Windows XP & 22.7 \\
\hline 8 & TCP/IP & 22.0 \\
\hline 9 & WAN & 22.0 \\
\hline 10 & VB & 21.2 \\
\hline 11 & Oracle & 20.5 \\
\hline 12 & PC Tech & 18.2 \\
\hline 13 & Java & 18.2 \\
\hline 14 & MS-SQL & 15.9 \\
\hline 15 & MS-Exchange & 15.2 \\
\hline 16 & MS-Office & 15.2 \\
\hline 17 & HTML & 14.4 \\
\hline 18 & MS-IIS & 13.6 \\
\hline 19 & MS-ASP & 12.1 \\
\hline 20 & .Net & 11.3 \\
\hline 21 & MySQL & 11.3 \\
\hline $\mathrm{n}=132$ & \multicolumn{2}{|l}{} \\
\hline
\end{tabular}

\section{Top Skills and Technical Knowledge for Systems Analysis Jobs}

Among jobs requiring systems analysis skills, about 62 percent also required some database skills. As Table 5 indicates, after written and verbal communications, knowledge of SQL was the individual skill most frequently listed.

Appearing in less than 8 percent of the job postings, the next most listed skills in descending order were: LAN skills, SAP, C programming, WebSphere, Crystal Reports, ERP, MS-IIS, Perl, and XML. Surprisingly, formal modeling skills were rarely mentioned for the jobs related to systems analysis. Only one job in the entire sample listed UML as a desired skill. A similar result, but not quite so extreme, was found in a recent study of on-line postings for systems analysis jobs [5]. 
Table 5. Top Systems Analysis Related Skills and Knowledge

\begin{tabular}{|c|l|c|}
\hline Rank & Skill/Knowledge & Percent \\
\hline 1 & $\begin{array}{l}\text { Written \& } \\
\text { Communications }\end{array}$ & 54.9 \\
\hline 2 & SQL & 37.7 \\
\hline 3 & Windows Server & 31.1 \\
\hline 4 & Oracle & 23.8 \\
\hline 5 & Linux/Unix/ Sol. & 23.0 \\
\hline 6 & MS-SQL & 21.3 \\
\hline 7 & Visual Basic & 19.7 \\
\hline 8 & PC Technology & 18.9 \\
\hline 9 & MS-Office & 17.2 \\
\hline 10 & Java & 14.8 \\
\hline 11 & Access & 13.9 \\
\hline 12 & Excel & 13.1 \\
\hline 13 & Web Design & 13.1 \\
\hline 14 & Windows XP & 13.0 \\
\hline 15 & HTML & 11.5 \\
\hline 16 & .Net & 10.7 \\
\hline 17 & MS-ASP & 9.0 \\
\hline 18 & MS-Exchange & 9.0 \\
\hline 19 & TCP/IP & 9.0 \\
\hline 20 & WAN & 9.0 \\
\hline $\mathrm{n}=122$ & & \\
\hline
\end{tabular}

Top Skills and Technical Knowledge for Programming Jobs

Visual Basic, listed in 44 percent of the programming related job postings, held a significant advantage over Java, with about 38 percent of the job listings. The importance of database development is reflected in the high demand for SQL.

Although more of the development seems to be in the Visual Basic, knowledge of Linux/Unix/Solaris was significantly higher than in the overall job market. Following on this list were: LAN Knowledge, Windows XP, SAN, Cobol, MS-IIS, WAN, WebShepre, Crystal Reports, and MS-Exchange.

\section{Cluster Analysis of Job Skills and Knowledge}

A cluster analysis of the job skills revealed only three natural clusters summarized in Table 7: a cluster that can be called business analysis, and clusters for programming, and networking. Systems analysis was not an automatic cluster, but was distributed throughout the three clusters. Database was also not a natural cluster, but distributed mostly through cluster one and two.
Table 6. Top Programming Related Skills and Knowledge

\begin{tabular}{|c|l|c|}
\hline Rank & Skill/Knowledge & Percent \\
\hline 1 & $\begin{array}{l}\text { Written \& Verbal } \\
\text { Communication }\end{array}$ & 52.8 \\
\hline 2 & Visual Basic & 44.4 \\
\hline 3 & SQL & 42.3 \\
\hline 4 & Java & 38.0 \\
\hline 5 & Team Work & 36.1 \\
\hline 6 & Linux/Unix/Sol. & 31.5 \\
\hline 7 & Windows Server & 27.8 \\
\hline 8 & HTML & 26.0 \\
\hline 9 & MS-ASP & 24.1 \\
\hline 10 & MS-SQL & 23.2 \\
\hline 11 & .NET & 23.1 \\
\hline 12 & C & 23.1 \\
\hline 13 & Oracle & 21.3 \\
\hline 14 & MS-Access & 17.6 \\
\hline 15 & TCP/IP & 14.8 \\
\hline 16 & MS-Office & 13.9 \\
\hline 17 & Web Design & 13.9 \\
\hline 18 & XML & 13.9 \\
\hline 19 & MS-Excel & 12.0 \\
\hline 20 & PC-Technology & 12.0 \\
\hline 21 & Perl & 12.0 \\
\hline $\mathrm{n}=108$ & \multicolumn{2}{|l}{} \\
\hline
\end{tabular}

Table 7. Major Job Areas from Cluster Analysis

\begin{tabular}{|c|l|c|}
\hline Cluster & Job Area & Percent \\
\hline 1 & Business Analysis & 42.0 \\
\hline 2 & Programming & 29.2 \\
\hline 3 & Networking & 28.8 \\
\hline
\end{tabular}

As indicated in Table 8 which reports the skills that significantly (95\%) determined the clusters, the first cluster is characterized particularly by required skills in Excel. Also significantly, this cluster does not require many of the more technical skills in networking and programming. Cluster 1 was primarily identified by skills not required, indicated by a No in the "Require" column of Table 8 . Skills are listed in descending order of their significance in identifying the cluster. Only skills with a 95 percent significance or higher are listed in the tables.

Other skills that tended to be required in Cluster 1 were MS-Office, SAS, and Systems Analysis. Database skills were also found in this group including SQL and Oracle. Database skills tended to be spread across the first two clusters. Cluster 1 had a modestly higher concentration of systems analysis skills than the other clusters. 
Table 8. Skills Significantly Identifying Cluster 1, Business Analysis

\begin{tabular}{|c|l|c|}
\hline Rank & Job Area & Require \\
\hline 1 & Windows Server & No \\
\hline 2 & Linux/Unix/Sol. & No \\
\hline 3 & Java & No \\
\hline 4 & Excel & YES \\
\hline 5 & LAN Knowledge & No \\
\hline 6 & Windows XP & No \\
\hline 7 & WAN Knolwedge & No \\
\hline 8 & ASP & No \\
\hline 9 & C & No \\
\hline 10 & TCP/IP & No \\
\hline 11 & Visual Basic & No \\
\hline 12 & Access & YES \\
\hline
\end{tabular}

Cluster 2 tracks with the traditional programming career path. All of the skills significantly identified as being included in this group are programming or development tools. Visual Basic scored just below the $95 \%$ reliability cutoff used for this analysis.

Table 9. Skills Significantly Identifying Cluster 2, Programming

\begin{tabular}{|l|l|l|}
\hline Rank & Skill & Require \\
\hline 1 & Java & YES \\
\hline 2 & MS-ASP & YES \\
\hline 3 & C & YES \\
\hline 4 & .NET & YES \\
\hline 5 & Perl & YES \\
\hline 6 & XML & YES \\
\hline 7 & SQL & YES \\
\hline 8 & HTML & YES \\
\hline
\end{tabular}

Cluster 3 includes standard networking skills and knowledge such as Windows Server, XP, LAN, and WAN. Skills significantly not included in this group were Oracle and SQL. There appears to be a clear divide between the networking and database skills, while database skills are contained in both the other clusters.

\section{CONCLUSIONS}

The data provide an approximate priority for skills in the overall market and for four market segments. As part of the curriculum design in our department, the curriculum committee created a skills/course matrix that mapped the top 20 overall skills into our required and elective classes to see where coverage might be fine tuned. One result, given the consistently high ranking for written and verbal communications, all faculty agreed to provide more opportunities for students to develop their communications skills in every course.

Table 10. Skills Significantly Identifying Cluster 3: Networking

\begin{tabular}{|l|l|l|}
\hline Rank & Skill & Require \\
\hline 1 & Windows Server & YES \\
\hline 2 & Windows XP & YES \\
\hline 3 & LAN & YES \\
\hline 4 & WAN & YES \\
\hline 5 & Novell & YES \\
\hline 6 & Linux/Unix/Sol. & YES \\
\hline 7 & VPN & YES \\
\hline 8 & Oracle & No \\
\hline 9 & SAN & YES \\
\hline 10 & Exchange & YES \\
\hline 11 & TCP/IP & YES \\
\hline 12 & SQL & No \\
\hline
\end{tabular}

In terms of technical skills, we found that attention to operating systems such as Windows and Linux seemed to be underrepresented in our curriculum compared to market demand. The networking courses were revised to include more of this content.

Since significant demand was found for both Visual Basic and Java, both of these languages are currently represented in the curriculum. We found strong demand for enterprise skills, such as Oracle and MSSQL in the survey, and have planned to add exposure to these applications in our database courses which have largely relied on MS-Access.

The level of employer interest in general systems analysis skills supported by software such as MSExcel were and MS-Office was somewhat surprising to the faculty. These skills have been given greater emphasis in the curriculum.

As a result of the cluster analysis, we have tried to emphasize the wide application of database related knowledge to both programming and systems analysis jobs. The result suggests that students with a database career path in mind will be expected to have a variety of additional skills related to programming and even networking. The students interested in networking, however, may find it useful for a focused approach.

While most faculty thought this exercise of attempting to map current market demand for skills against our curriculum was useful, a dissenting voice suggested that skills change so rapidly that we should focus more on concepts and not worry so much about 
the specific skills used to illustrate fundamental knowledge. Having personally invested significant time in learning to program in FORTRAN as a result of one curriculum that might have gotten a little out of date, the author plans to continue this line of research.

\section{REFERENCES}

1. Gorgone, J.T., Davis, G. B., Topi, H., Feinsten, D. L., \& Longenecker, H. E. Jr. (2002). IS2002: Model Curriculum and Guidelines for Undergraduate Degrees Programs in Information Systems. ACM [online] http://www.acm.org/education/is2002.pdf

2. Tang, H., Lee, S., Koh, S. (1995). Educational gaps as perceived by IS educators: A survey of knowledge and skill requirements. Journal of Computer Information Systems, 41(2), 76-85.

3. Leitheiser, R. L. (1992). MIS skills for the 1990s: A Survey of MIS managers' perceptions. Journal of Management Information Systems, 92(1). 69-92.
4. Todd, P.A., Mckeen, J.D., \& Brent, R. (1995). The evolution of IS job skills: A content analysis of IS job advertisements from 1970 to 1990 . MIS Quarterly, 19(3), 1-27.

5. Lee, C.K. (2005). Analysis of skill requirements for systems analysts in Fortune 500 Companies, Journal of Computer Information Systems, 45(4), 84-92.

6. Webb, G.K. (2005). An estimate of demand for MIS skills. Proceedings of the Decision Sciences Institute.

7. Fox, T.L, Hindi, N., \& Remington,W.S. (2001). Student's perceptions and misconceptions of a career in IS. Journal of Computer Information Systems, 42(1). 83-90.

8. Litecky, C.R., Arnett, K.P., \& Bibpin, P. (2004). The paradox of soft skills versus technical skills in IS hiring. Journal of Computer Information Systems, 45(1). 69-76. 